\title{
Ultramicrotomy of Polymers Using an Oscillating Diamond Knife; Improving Polymer Morphology.
}

\author{
J.S.J. Vastenhout* and H. Gnägi**. \\ *Dow Benelux B.V., Analytical Sciences, MC-SMX Discipline, P.O. Box 48, \\ 4530 AA Terneuzen, The Netherlands. \\ ** Diatome Ltd Switzerland, P.O. Box 557, CH-2501 Biel, Switzerland.
}

Sample preparation is one of the crucial steps for successful transmission electron microscopy (TEM) and atomic force microscopy (AFM) investigations of polymers. Some of the typically encountered complications include ability to obtain very thin sections (50 nm or less), compression of ultra thin sections, induced surface roughness, need of working at cryogenic temperatures etc. It is generally known that the ultramicrotomy procedure results in compres sion of the ultra thin sections. Ultramicrotomy of polymer materials done at room temperature using a diamond knife with a $45^{\circ}$ angle and the ultra thin sections floating on water results in an average compression of $20 \quad-40$ $\%$ depending the material. Reducing the knife angle results in lower compression [1]. Therefore nowadays it is common practice in materials ultramicrotomy of to use a diamond knife with a $35^{\circ}$ angle instead of $\mathrm{a}^{\circ}$ angle, which reduces the original compression with $33-50 \%$.

The compressi on of ultra thin sections increases when these sections are cryoultramicrotomed [2] due to the fact that there's no lubricating effect anymore of the water. Because a lot of polymeric materials need to be cryoultramicrotomed it is essential to lower the co

mpression as much as possible. The lower the compression, the better the morphology will be.

Recent developments in reducing the compression of ultra thin sections have lead to the invention of an oscillating diamond knife [3]. The oscillating diamond kni fe reduced the compression almost completely without additional cutting artifacts observed. A prototype of this oscillating diamond knife was evaluated and tested to prepare ultra thin sections of polymer materials both at room temperature and at cryo tem peratures. The ultra thin sections made with the oscillating diamond knife were compared with sections of the same sample but prepared with a $35^{\circ}$ angle diamond knife. A variety of polymer materials and blends were studied and for all materials an improveme nt of the morphology was observed. The overall morphology was better preserved and in some materials more detailed structure was visible that was normally destroyed by the sectioning procedure. An additional, but important advantage of the oscillating knif e is the possibility to section materials at room temperature that normally need to be sectioned at cryo temperatures (Fig.1,2). The elimination of the compression also results in flatter surfaces which are essential in the preparation of samples for AFM as well as the reduced section thickness, down to approximately $20 \mathrm{~nm}$, is.

\section{References}

[1] Jesior, J.-C., Scanning Microscopy (Suppl.3) (1989) 147-153.

[2] Richter, K., Micron 25 (1994) 297-308.

[3] Studer, D. and Gnägi, H., Journal of Microscopy 197 (2000) 94-100.

[4] We would like to thank Dr. Daniel Studer of the Institute of Anatomy of the University of Berne, Switzerland for his editorial comments and contribution in the discussion of the results. 

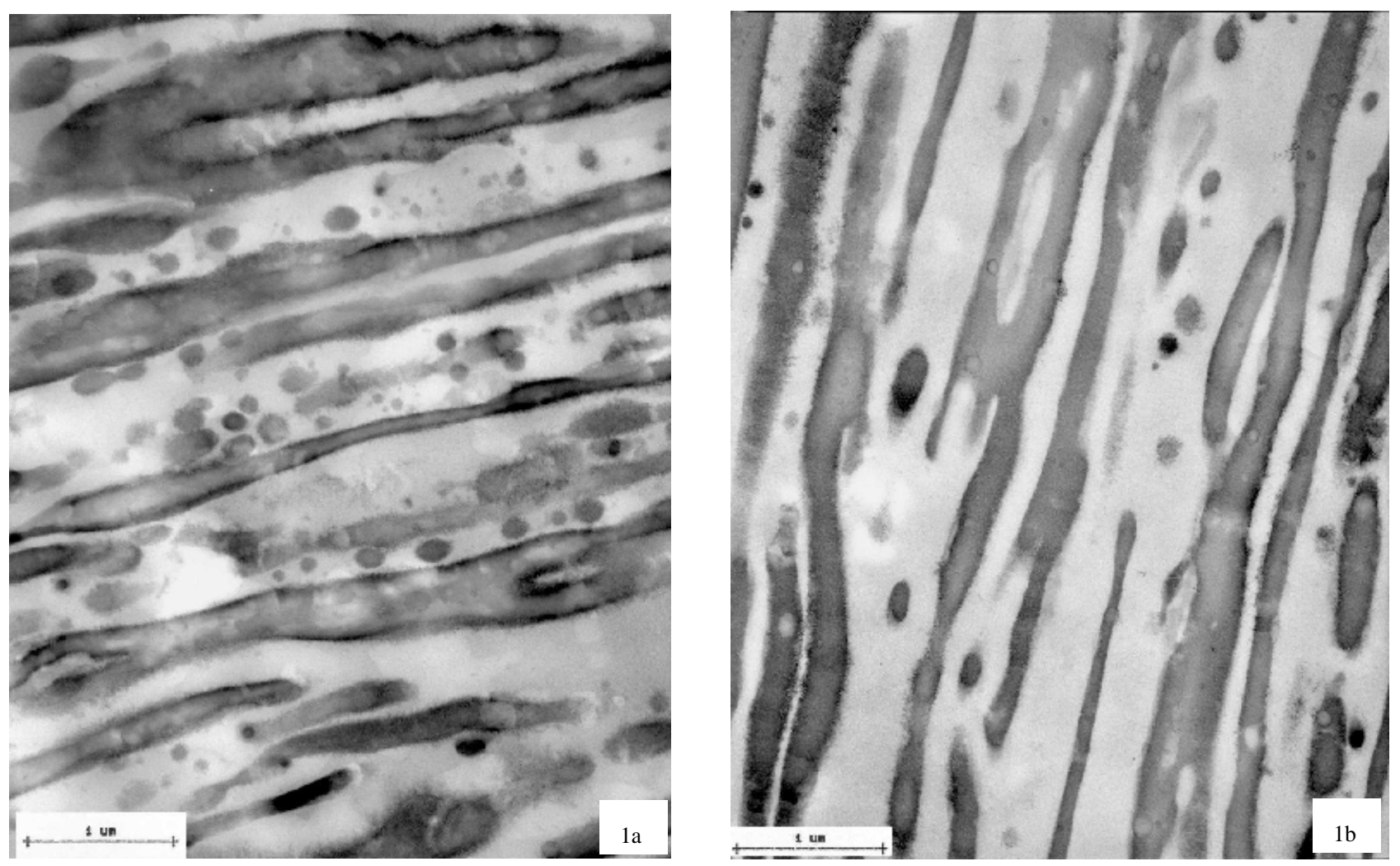

FIG. 1 Blend of polypropylene and polyethylene (a) sectioned at room temperature using a $35^{\circ}$ angle diamond knife, (b) sectioned at room temperature using an oscillating diamond knife.
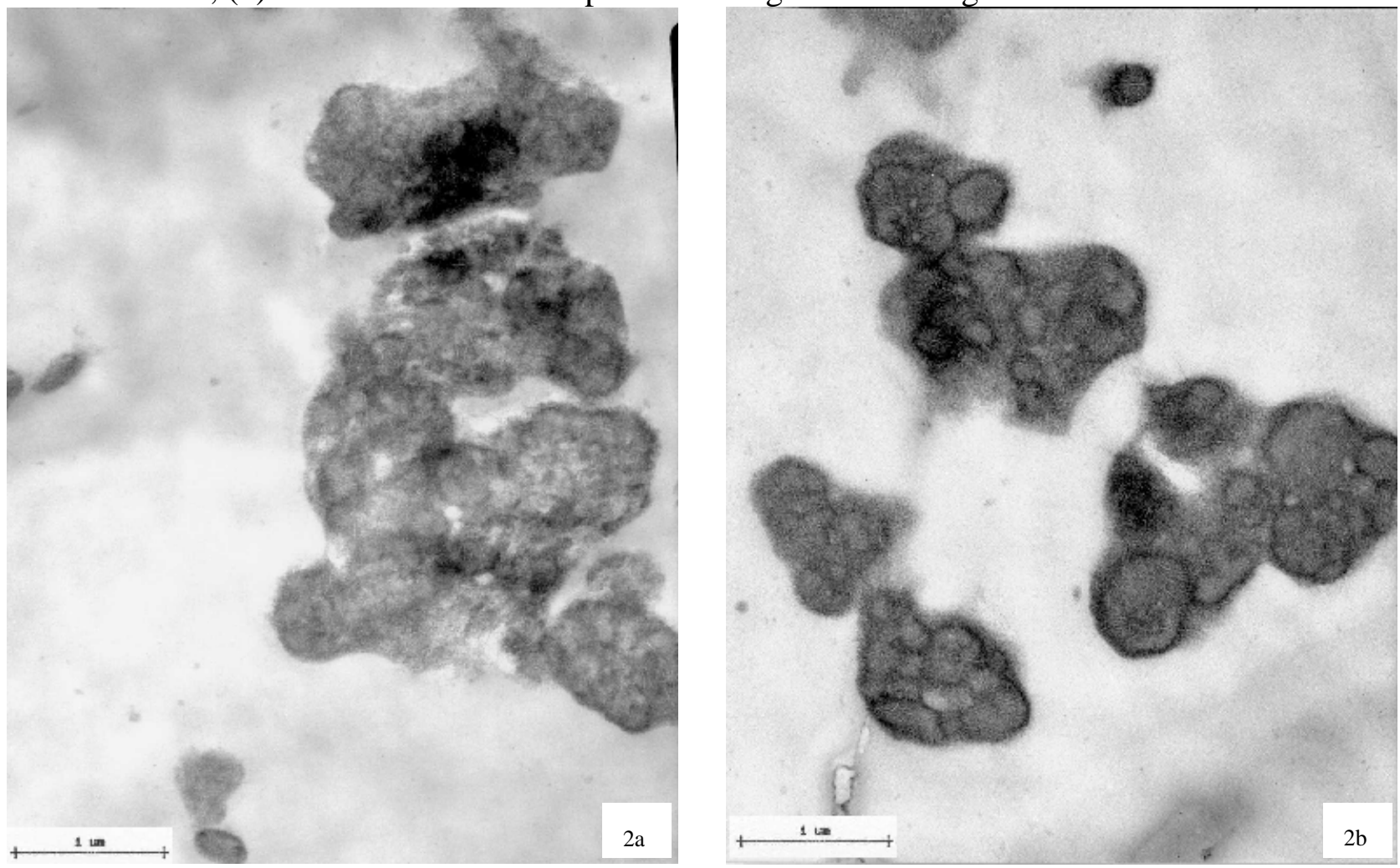

FIG. 2. Impact modified polypropylene (a) sectioned at room temperature using a $35^{\circ}$ angle diamond knife, (b) sectioned at room temperature using an oscillating diamond knife. 